\title{
Desulfonispora thiosulfatigenes gen. nov., sp. nov., a taurine-fermenting, thiosulfate-producing anaerobic bacterium
}

\author{
Karin Denger, ${ }^{1}$ Erko Stackebrandt ${ }^{2}$ and Alasdair M. Cook ${ }^{1}$
}

Author for correspondence: Alasdair M. Cook. Tel: +497531 88 4247. Fax: +497531882966. e-mail: alasdair.cook@uni-konstanz.de

\footnotetext{
1 Fakultät für Biologie der Universităt, D-78457 Konstanz, Germany

2 DSMZ - Deutsche Sammlung von Mikroorganismen und Zellkulturen $\mathrm{GmbH}$, Mascheroder Weg $1 \mathrm{~b}$, D-38124 Braunschweig, Germany
}

\begin{abstract}
Strain GKNTAU' has been described as a bacterium able to ferment the organosulfonate taurine (2-aminoethanesulfonate) quantitatively to acetate, ammonia and thiosulfate, an unusual metabolic product. This novel fermentation has now also been observed in four independent isolates from two continents. All five organisms were strictly anaerobic, Gram-positive, motile, spore-forming bacteria. Enrichments with isethionate (2hydroxyethanesulfonate) and cysteate (2-amino-3-sulfopropionate), in contrast, yielded bacteria that disproportionated the sulfonate to sulfate and sulfide. The phylogenetic location of the taurine fermenters was analysed on the basis of 16S rDNA sequences. Strain GKNTAU' ( = DSM 11270' $=$ ATCC 700533') is described as the type strain of a new genus and species, for which the name Desulfonispora thiosulfatigenes gen. nov., sp. nov. is proposed.
\end{abstract}

Keywords: Desulfonispora thiosulfatigenes, taurine, thiosulfate, sulfonate, anaerobic desulfonation

\section{INTRODUCTION}

The first fermentation of an organosulfonate compound (i.e. containing the stable $\mathrm{C}-\mathrm{SO}_{3}^{-}$bond) was reported recently (Denger et al., 1997b; Cook et al., 1998) and involved the major mammalian solute taurine (2-aminoethanesulfonate) (cf. Huxtable, 1992). This novel anaerobic reaction by the bacterial strain GKNTAU ${ }^{\mathrm{T}}$ yielded acetate, ammonia and thiosulfate as quantitative metabolic products. This type of fermentation, if widespread, was proposed as a potential environmental source of thiosulfate (Denger et al., 1997b), whose other known source as an end product of a degradative pathway is Aquamicrobium defluvii (Bambauer et al., 1998). Thiosulfate is otherwise known as a widely used electron acceptor or donor by many aerobic and anaerobic bacteria.

A second bacterial fermentative reaction with an organosulfonate, a disproportionation of e.g. cysteate (2-amino-3-sulfopropionate) to yield sulfate and sulfide (as well as acetate and ammonia), has also been

\footnotetext{
Abbreviations: CoM, coenzyme $M$; CYS, cysteate; ISE, isethionate; LK, Lake Konstanz; PU, Pushchino; RZ, Radolfzell; SU, Sunnyvale; TAU, taurine. The GenBank/EMBLDDBJ accession number for the 16S rDNA sequence from Desulfonispora thiosulfatigenes DSM $11270^{\top}$ is $Y 18214$.
}

discovered (Laue et al., 1997a). It is thus relevant to establish whether the reaction found in strain GKNTAU $^{\mathrm{T}}$ is widespread or limited to the inoculum that we used in the initial work.

On the basis of a partial 16S rDNA sequence (Denger et al., 1997b), strain GKNTAU ${ }^{\mathrm{T}}$ was described as representing a novel genus in the Syntrophomonas assemblage within the Clostridium subdivision of the Gram-positive bacteria. In this communication, we present data on the widespread occurrence of relatives of strain GKNTAU ${ }^{\mathrm{T}}$ for which the name Desulfonispora thiosulfatigenes gen. nov., sp. nov. is proposed.

\section{METHODS}

Enrichment, isolation and culture conditions. Enrichment cultures were made under aseptic conditions. Strictly anoxic conditions, confirmed by the absence of colour in the presence of $2 \mu \mathrm{M}$ resazurine, were maintained in bicarbonate-buffered, titanium(III) nitrilotriacetate-reduced mineral salts medium at $\mathrm{pH} 7 \cdot 0$, which contained a single sulfonate as the sole source of carbon and energy as described previously (Denger et al., 1997b). Cultures were incubated with occasional shaking at $30^{\circ} \mathrm{C}$ in the dark. Putative enrichments were subcultured four or five times before bacteria were isolated by the agar shake method (Pfennig, 1978). 
Table 1. Evaluation of the enrichment cultures

All cultures were anoxic, as indicated by the colourless resazurine redox indicator. The abbreviations indicate where stable enrichment cultures were obtained; the coding is a combination of the inoculum and the substrate utilized: taurine (TAU); cysteate (CYS); isethionate (ISE). - , No growth after 7 weeks incubation.

\begin{tabular}{|c|c|c|c|c|}
\hline Geographic origin of inoculum & Taurine & Cysteate & Isethionate & Coenzyme $\mathbf{M}$ \\
\hline Sewage works, Radolfzell (RZ), Germany & RZ/TAU & - & - & - \\
\hline Sewage works, Pushchino (PU), Russia & $\mathrm{PU} / \mathrm{TAU}$ & PU/CYS & PU/ISE & - \\
\hline $\begin{array}{l}\text { Sewage works, Sunnyvale (SU), California, } \\
\text { USA }\end{array}$ & SU/TAU & SU/CYS & SU/ISE & - \\
\hline Pool, Arastradero Lake, California, USA & - & - & - & - \\
\hline Creek, Ronda, Spain & - & - & - & - \\
\hline Sediment of Lake Konstanz (LK), Germany & LK/TAU & - & - & - \\
\hline
\end{tabular}

The inocula were from six sources (Table 1). Three samples originated from anaerobic digesters integrated in communal sewage works in Germany (RZ), Russia (PU) and California (SU), while two samples came from small freshwater habitats in Spain and California. Sample LK was derived from a lake sediment under an $80 \mathrm{~m}$ water column. The sampling sites for strains RZ and LK were in the Rhine basin, upstream of the sewage works in Konstanz from which strain GKNTAU $^{\mathrm{T}}$ was isolated (strain LK) or from a separate section of Lake Konstanz (Radolfzell) where no mixing of water samples is likely (strain RZ). The freshwater samples, when used for enrichments, were no longer black (putative iron sulfide) but were brown. Strain GKNTAU ${ }^{\mathrm{T}}$ (= DSM $11270^{\mathrm{T}}=\mathrm{ATCC} 700533^{\mathrm{T}}$ ) (Denger et al., 1997b) was already under study in the laboratory.

Morphology and physiology. Purity, morphology, motility and spore formation were checked microscopically. The Gram reaction was assayed in the $\mathrm{KOH}$ test (Gregersen, 1978). Oxidase and catalase tests were carried out according to standard methods (Gerhardt et al., 1994). Utilization of the bile acids taurochenodeoxycholate, taurodeoxycholate or taurocholate was tested with $3 \mathrm{mM}$ substrate each plus $3 \mathrm{mM}$ added after $3 \mathrm{~d}$.

Analytical methods. Taurine was derivatized and determined by reverse-phase HPLC (Denger et al., 1997a). Acetate was quantified by GC (Laue et al., 1997b). Ammonia was measured using the Berthelot reaction (Gesellschaft Deutscher Chemiker, 1996). Thiosulfate and sulfate were quantified by ion chromatography (Denger et al., 1997b), and sulfide was determined colorimetrically (Cline, 1969). Cytochromes in strain GKNTAU ${ }^{\mathrm{T}}$ were assayed in soluble and membrane fractions obtained after disruption of cells in a French press and a number of centrifugation steps (Denger et al., 1997b). Redox-difference spectra of dithionite-reduced minus air-oxidized, or minus CO-reduced, samples were recorded with a Uvicon 922 spectrophotometer. The concentration of cytochrome $b$ was calculated from the absorbance difference $\Delta \mathrm{E}_{561}-\Delta \mathrm{E}_{575}$, assuming a $\Delta \varepsilon_{561-575}$ of $26.2 \mathrm{mM}^{-1} \mathrm{~cm}^{-1}$ (Kröger \& Innerhofer, 1976). SDS-PAGE with $4 \%$ stacking gels and $10 \%$ separating gels was performed using a standard method (Laemmli, 1970) with Coomassie staining. Protein was assayed using a dye-binding method (Bradford, 1976). The $\mathrm{G}+\mathrm{C}$ content of DNA was determined by HPLC in the DSMZ service laboratory.

165 rDNA sequencing Extraction of genomic DNA, PCRmediated amplification of $16 \mathrm{~S}$ rDNA, purification of the
PCR products, and sequence analysis were performed as described elsewhere (Rainey et al., 1996). Sequence reactions were electrophoresed using the Applied Biosystems 373A DNA sequencer. The sequence was aligned manually to $16 \mathrm{~S}$ rRNA gene sequences of representative micro-organisms belonging to the domain Bacteria using the alignment editor ae2 (Maidak et al., 1996). A phylogenetic tree was generated using the alogorithm of De Soete (1983) - accession numbers are given in Fig. 3.

\section{RESULTS AND DISCUSSION}

\section{Enrichment and isolation}

Anoxic enrichment cultures were set up with $10 \mathrm{mM}$ organosulfonate as the sole source of carbon and energy for six different inocula (Table 1). After incubation for 1 week, the first cultures developed turbidity, and bacteria could be observed microscopically. In total, eight enrichment cultures were obtained. All cultures utilizing taurine grew in $18-48 \mathrm{~h}$ when transferred regularly; the other cultures required about $5 \mathrm{~d}$. After four to five transfers in homologous medium, each culture was dominated by a single organism. Thus it was easy to obtain bacteria, which ferment the natural products taurine (four enrichments), cysteate (two enrichments) and isethionate (2-hydroxyethanesulfonate; two enrichments) from inocula from different continents. Not all of the enrichments produced all of the end products found in samples from Sunnyvale and Pushchino (Table 1). The widespread coenzyme $\mathbf{M}$ was not dissimilated in any anaerobic organism tested (Lie et al., 1996; Denger et al., 1997a; Laue et al., 1997b).

The fate of the sulfonate moiety was examined in each of the eight enrichments. The isethionate-utilizing and the cysteate-utilizing cultures produced a mixture of sulfide and sulfate, which is analogous to the end products of Desulfovibrio sp. strain GRZCYSA (Laue et al., 1997a). While the isethionate-utilizing strains were vibrioform, the cysteate-utilizing cultures were spirilliform or rods. No spores were detected in the latter cultures. 


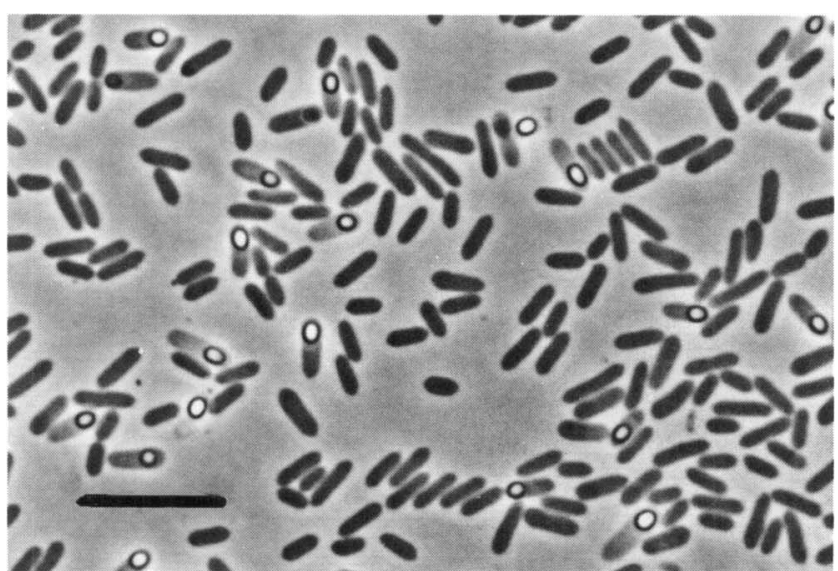

Fig. 1. Phase-contrast photomicrograph of strain GKNTAU after growth in taurine mineral salts medium. Bar, $10 \mu \mathrm{m}$.

All of the four cultures that utilized taurine produced thiosulfate. Thus, as in our previous work on GKNTAU $^{\mathrm{T}}$ (Denger et al., 1997b), we find only two patterns of energy conservation in the fermentation of organosulfonates, i.e. the formation of thiosulfate from sulfite in taurine metabolism (analogous to strain GKNTAU $^{\mathrm{T}}$ ) and the disproportionation of putative sulfite to sulfate and sulfide in the metabolism of cysteate and isethionate (analogous to strain GRZCYSA).

A single organism was isolated from each of the taurine enrichment cultures and each isolate was a motile, spore-forming rod similar to strain GKNTAU $^{\mathrm{T}}$. The organisms were $2-5 \times 0.7-1 \cdot 0 \mu \mathrm{m}$ in size and formed subterminal spores. A phase-contrast photomicrograph of strain GKNTAU ${ }^{\mathrm{T}}$ is shown in Fig. 1. The isolates were Gram-positive and oxidasenegative. Most were catalase-negative, except for strain SU/TAU. The pattern of proteins from crude extracts of all five strains after separation on SDSPAGE was almost indistinguishable (not shown). The fermentation products from taurine were always equimolar amounts of acetate and ammonia together with $0.5 \mathrm{~mol}$ thiosulfate, as found with strain GKNTAU ${ }^{\mathrm{T}}$ (Denger et al., 1997b), so we consider that the same formal dissimilatory mass balance applies:

$$
\begin{aligned}
& 2 \mathrm{C}_{2} \mathrm{H}_{7} \mathrm{NSO}_{3}+1 \mathrm{H}_{2} \mathrm{O} \rightarrow \\
& \qquad \mathrm{C}_{2} \mathrm{H}_{3} \mathrm{O}_{2}^{-}+2 \mathrm{NH}_{4}^{+}+\mathrm{S}_{2} \mathrm{O}_{3}^{2-}+2 \mathrm{H}^{+} .
\end{aligned}
$$

Neither sulfide nor sulfate was found in these cultures (as in Desulfovibrio sp. strain GRZCYSA; Laue et al., 1997a). Thus all isolates that ferment taurine use the same overall pathway. None of these isolates grew with the three naturally occurring organosulfonates (cysteate, isethionate and coenzyme M).

\section{Physiological properties of strain GKNTAU}

This bacterium has become specialized for taurine fermentation, as none of the 36 carbon substrates tested supported growth (Denger et al., 1997b). Bile

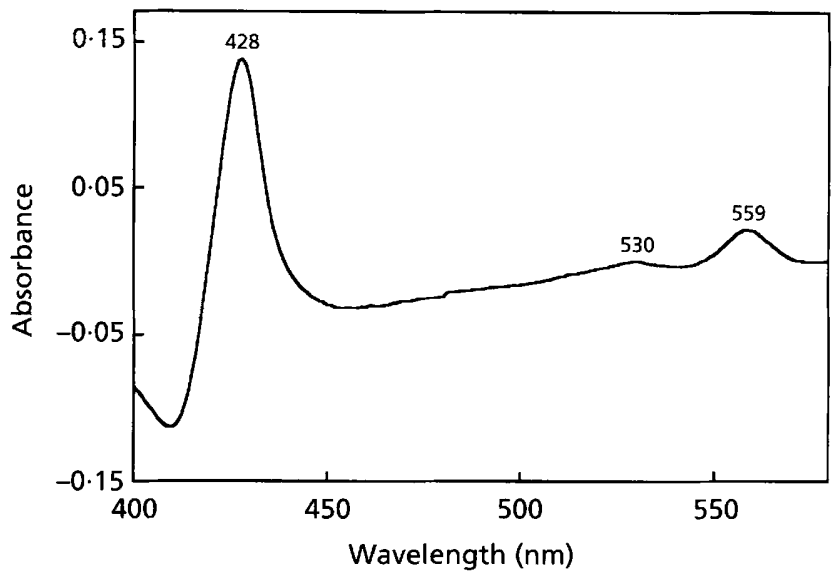

Fig. 2. Redox-difference spectrum of the membrane fraction of strain GKNTAU ${ }^{\top}$ showing the spectrum of cytochrome $b$. The protein concentration was $1.3 \mathrm{mg} \mathrm{ml}^{-1}$.

acids, e.g. taurochenodeoxycholate, taurodeoxycholate or taurocholate, demonstrated to be utilized by the taurine-reducing bacterium Bilophila wadsworthia RZATAU (Schumacher et al., 1996), did not support growth. Sulfoacetate, 3-aminopropanesulfonate and $\beta$-alanine (each at $20 \mathrm{mM}$ ) were not utilized. Complex media, $0.2 \%(\mathrm{w} / \mathrm{v})$ tryptone and $0.1 \%(\mathrm{w} / \mathrm{v})$ yeast extract also failed to support growth of strain GKNTAU ${ }^{\mathrm{T}}$.

As it can be assumed that conservation of energy coupled to the formation of thiosulfate involves electron transport, the reddish-brown cell-free extracts of strain GKNTAU ${ }^{T}$ were tested for the presence of cytochromes. Absorption bands at 428,530 and $559 \mathrm{~nm}$ (Fig. 2) were detected in both soluble and membrane fractions, which indicated the presence of $b$-type cytochromes (Voet \& Voet, 1992). The content of cytochrome $b$ in the soluble fraction was calculated to be about $0.08 \mu \mathrm{mol}(\mathrm{g} \text { protein })^{-1}$, while the level of cytochrome $b$ in the membrane was about $0.6 \mu \mathrm{mol}(\mathrm{g}$ protein $)^{-1}$. Thus we attributed membrane-bound cytochrome $b$ to a putative electron-transport chain involved in generating thiosulfate.

The source of the sulfur atoms in the thiosulfate synthesized by strain GKNTAU ${ }^{\mathrm{T}}$ is sulfite (Denger $e t$ al., 1997b), and a sulfite reductase was proposed to be involved in the pathway leading to thiosulfate (Denger et al., 1997b). Difference spectra obtained in this study gave no support for the presence of desulforubidin (Lien \& Beeder, 1997) or desulfofuscidin (Hatchikian \& Zeikus, 1983). 'Shoulders' in the UV-visible spectrum of the oxidized form at 383 and $580 \mathrm{~nm}$ (literature values 383 and $581 \mathrm{~nm}$ ), however, were preliminary evidence for a P582 sulfite reductase (Trudinger, 1970). This assumption was supported by oxidized minus dithionite-reduced difference spectra with minima at 446 and $580 \mathrm{~nm}$ and maxima at 558 and $622 \mathrm{~nm}$ (literature values $450,581,557$ and $621 \mathrm{~nm}$ ), and by characteristic difference spectra with $\mathrm{CO}$ (a minimum 


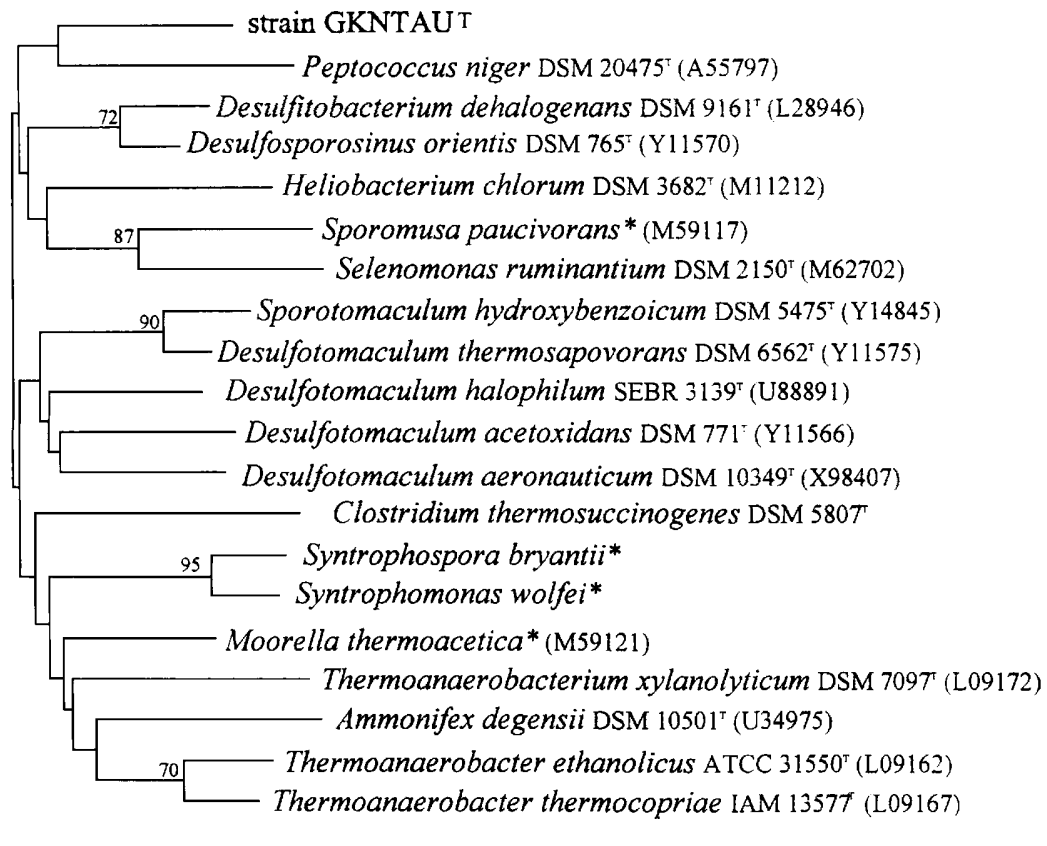

$10 \%$
Fig. 3. Phylogenetic dendrogram based on 16S rDNA sequence similarities between strain GKNTAU ${ }^{\top}$ and the nearest related taxa (De Soete, 1983). Bar, 10\% sequence similarity. * Sequences derived from the Ribosomal Database Project (Maidak et al., 1997). at $432 \mathrm{~nm}$ and a maximum at $594 \mathrm{~nm}$ (literature values 432 and $596 \mathrm{~nm}$ ); cytochrome $b$ interfered at other key parts of the spectrum.

\section{Phylogenetic analysis}

The almost complete $16 \mathrm{~S}$ rDNA sequence of strain GKNTAU $^{\mathrm{T}}$ consisting of 1507 nucleotides was compared with currently available sequences of representative prokaryotes belonging to the domain Bacteria. Strain GKNTAU ${ }^{\mathrm{T}}$ belongs to the Clostridium subdivision of the Gram-positive bacteria, but shows less than $88 \%$ sequence similarity with any of the deposited sequences. The highest values of $86-88 \%$ similarity are found with sequences from members of the genera Desulfotomaculum, Desulfitobacterium, Desulfosporosinus and Peptococcus. A relationship dendrogram (De Soete, 1983) demonstrates the position of strain GKNTAU $^{\mathrm{T}}$ next to its nearest neighbours (Fig. 3). Bootstrap values are low for the majority of branch points, including that leading to strain GKNTAU ${ }^{\mathrm{T}}$ and Peptococcus niger. The low level of relatedness to the most closely related species and the lack of physiologically similar organisms in the phylogenetic neighbourhood led us to the conclusion that the new thiosulfate-producing strain represents a new genus and species; the name Desulfonispora thiosulfatigenes gen. nov., sp. nov., with strain GKNTAU ${ }^{\mathrm{T}}$ (= DSM $11270^{\mathrm{T}}=\mathrm{ATCC} 700533^{\mathrm{T}}$ ) as the type strain, is proposed. The strains RZ/TAU, PU/TAU, SU/TAU and LK/TAU are affiliated to this species because of the high similarities in physiological and morphological properties.

The $\mathrm{G}+\mathrm{C}$ content of strain GKNTAU ${ }^{\mathrm{T}}$ was determined to be $52 \mathrm{~mol} \%$. This value falls within the range of the Clostridium subdivision $(21-54 \mathrm{~mol} \%$; Hippe et al., 1992), which is widely considered to have a low $\mathrm{G}+\mathrm{C}$ content.

\section{Description of Desulfonispora thiosulfatigenes gen. nov., sp. nov.}

Desulfonispora thiosulfatigenes [De.sul.fo.ni.spo'ra. M.L. pref. desulfono desulfonating; L. fem. n. spora spore; M.L. fem. n. Desulfonispora desulfonating spore (-former); thi.o.sul.fa.ti'ge.nes. M. L. n. thiosulfas thiosulfate; M.L. suff. genes -producing; M.L. part. adj. thiosulfatigenes thiosulfate-producing].

Rod-shaped bacteria, $2-5 \times 0 \cdot 7-1 \cdot 0 \mu \mathrm{m}$ in size, motile, with subterminal spores. Oxidase- and catalase-negative. High cytochrome $b$ level in membrane fractions. Mesophilic. Growing only with taurine (out of 41 substrates tested), producing acetate, ammonia and thiosulfate. Neither sulfate, sulfite nor nitrate is reduced. In terms of phylogeny, the type species is a member of the Clostridium subline of descent, being remotely related to Peptococcus, Desulfotomaculum, Desulfitobacterium and Desulfosporosinus. The G+C content is $52 \mathrm{~mol} \%$. Strain GKNTAU ${ }^{\mathrm{T}}$ is the type strain and is deposited with the DSMZ (Deutsche Sammlung von Mikroorganismen und Zellkulturen) under DSM $11270^{\mathrm{T}}$ and with the American Type Culture Collection under ATCC $700533^{\mathrm{T}}$.

\section{REFERENCES}

Bambauer, A., Rainey, F. A., Stackebrandt, E. \& Winter, J. (1998). Characterization of Aquamicrobium defluvii gen. nov. sp. nov., a thiophene-2-carboxylate-metabolizing bacterium from activated sludge. Arch Microbiol 169, 293-302. 
Bradford, M. M. (1976). A rapid and sensitive method for the quantitation of microgram quantities of protein utilizing the principle of protein-dye binding. Anal Biochem 72, 248-254.

Cline, J. D. (1969). Spectrophotometric determination of hydrogen sulfide in natural waters. Limnol Oceanogr 14, 454 458.

Cook, A. M., Laue, H. \& Junker, F. (1998). Microbial desulfonation. FEMS Microbiol Rev 22, 399-419.

Denger, K., Laue, H. \& Cook, A. M. (1997a). Anaerobic taurine oxidation: a novel reaction by a nitrate-reducing Alcaligenes sp. Microbiology 143, 1919-1924.

Denger, K., Laue, H. \& Cook, A. M. (1997b). Thiosulfate as a metabolic product: the bacterial fermentation of taurine. Arch Microbiol 168, 297-301.

De Soete, G. (1983). On the construction of 'optimal' phylogenetic trees. $Z$ Naturforsch $C$ : Biosci 38, 156-158.

Gesellschaft Deutscher Chemiker (1996). German Standard Methods for the Laboratory Examination of Water, Waste Water and Sludge. Weinheim: VCH.

Gerhardt, P., Murray, R. G. E., Wood, W. A. \& Krieg, N. R. (1994). Methods for General and Molecular Bacteriology. Washington, DC: American Society for Microbiology.

Gregersen, T. (1978). Rapid method for distinction of Gramnegative from Gram-positive bacteria. Eur J Appl Microbiol Biotechnol 5, 123-127.

Hatchikian, E. C. \& Zeikus, J. G. (1983). Characterization of a new type of dissimilatory sulfite reductase present in Thermodesulfobacterium commune. J Bacteriol 153, 1211-1220.

Hippe, H., Andreesen, J. R. \& Gottschalk, G. (1992). The genus Clostridium - nonmedical. In The Prokaryotes, pp. 1800-1878. Edited by A. Balows, H. G. Trüper, M. Dworkin, W. Harder \& K. H. Schleifer. Berlin: Springer.

Huxtable, R. J. (1992). Physiological actions of taurine. Physiol Rev 72, 101-163.

Kröger, A. \& Innerhofer, A. (1976). The function of the $b$ cytochromes in the electron transport from formate to fumarate of Vibrio succinogenes. Eur J Biochem 69, 497-506.
Laemmli, U. K. (1970). Cleavage of structural proteins during the assembly of the head of bacteriophage T4. Nature 227, 680-685. Laue, H., Denger, K. \& Cook, A. M. (1997a). Fermentation of cysteate by a sulfate-reducing bacterium. Arch Microbiol 168, 210-214.

Laue, H., Denger, K. \& Cook, A. M. (1997b). Taurine reduction in anaerobic respiration of Bilophila wadsworthia RZATAU. Appl Environ Microbiol 63, 2016-2021.

Lie, T. J., Pitta, T., Leadbetter, E. R., Godchaux, W., III \& Leadbetter, J. R. (1996). Sulfonates: novel electron acceptors in anaerobic respiration. Arch Microbiol 166, 204-210.

Lien, T. \& Beeder, J. (1997). Desulfobacter vibrioformis sp. nov., a sulfate reducer from a water-oil separation system. Int $J$ Syst Bacteriol 47, 1124-1128.

Maidak, B. L., Olsen, G. J., Larsen, N., Overbeek, R., McCaughey, M. J. \& Woese, C. R. (1996). The ribosomal database project (RDP). Nucleic Acids Res 24, 82-85.

Maidak, B. L., Olsen, G. J., Larsen, N., Overbeek, R., McCaughey, M. J. \& Woese, C. R. (1997). The RDP (Ribosomal Database Project). Nucleic Acids Res 25, 109-110.

Pfennig, N. (1978). Rhodocyclus purpureus gen. nov. sp. nov., a ring-shaped, vitamin $\mathrm{B}_{12}$-requiring member of the family Rhodospirillaceae. Int $J$ Syst Bacteriol 28, 283-288.

Rainey, F. A., Ward-Rainey, N., Kroppenstedt, R. M. \& Stackebrandt, E. (1996). The genus Nocardiopsis represents a phylogenetically coherent taxon and a distinct actinomycete lineage: proposal of Nocardiopsaceae fam. nov. Int $J$ Syst Bacteriol 46, 1088-1092.

Schumacher, U. K., Lutz, F. \& Werner, H. (1996). Taurine and taurine conjugated bile acids enhance growth of Bilophila wadsworthia. In Proceedings of the 21st International Congress on Microbial Ecology and Disease, Paris.

Trudinger, P.A. (1970). Carbon monoxide-reacting pigment from Desulfotomaculum nigrificans and its possible relevance to sulfite reduction. $J$ Bacteriol 104, 158-170.

Voet, D. \& Voet, J. G. (1992). Biochemie. Weinheim: VCH. 